\title{
PSICOLOGIA E ASSISTÊNCIA SOCIAL: DIÁLOGOS POSSÍVEIS
}

\section{Kairon Pereira de Araújo Sousa}

Universidade Federal do Piauí - UFPI
Recebido em: 16/02/2020

$1^{\text {a }}$ revisão em: 08/04/2020

Aceito em: 29/04/2020

Cruz, L. R., Guareschi, N. M. F., \& Battistelli, B. M. (Eds). (2019). Psicologia e assistência social: Encontros possíveis no contemporâneo. Petrópolis, RJ: Vozes.

\section{RESENHA}

A política pública de assistência social representa, na atualidade, um dos principais campos de emprego para psicólogos brasileiros, sendo uma das responsáveis pela expansão e interiorização da psicologia no país (Macedo \& Dimenstein, 2011). Apesar disso, tem se evidenciado uma escassez na produção científica nesse campo de atuação psicológica, no que se refere ao lançamento de livros que abordem acerca da relação entre a psicologia e a assistência social.

Em face dessa lacuna no conhecimento científico sobre a área supracitada, o livro Psicologia e assistência social: encontros possíveis no contemporâneo disponibiliza ao público leitor um conjunto de textos escritos por pesquisadores de diferentes partes do país que compõem uma visão crítica sobre temas centrais que atravessam a atuação de psicólogos na política de assistência social brasileira. A diversidade de temas abordados na obra é um ponto de destaque.

Outro aspecto, que merece ser apontado, é o formato diferenciado de escrita acadêmica presente em alguns dos trabalhos, a exemplo do capítulo introdutório (construído em forma de cartas) e do capítulo doze ("Rádio no livro") que apresenta um arranjo textual com desarticulações no corpo, formato e timbre da escrita. Estes escritos, distintos da redação acadêmica usual, nos instigam a pensar, conforme Bruna Battistelli e Lílian Cruz: "Quem disse que pesquisas precisam ter a mesma forma de escrita?". 
A atualidade das discussões também é um ponto forte do manuscrito. Os textos produzidos ecoam os debates atuais na interface psicologia e assistência social, conectando-se com as implicações do itinerário histórico, social e político do país, em uma convocação para pensarmos novas possibilidades de atuação em psicologia na política de assistência social.

Um ponto diferencial nesta obra, que poderá ser verificado pelo/a leitor/a, é que as discussões e experiências apresentadas não se restringem apenas à proteção social básica, operacionalizada no Centro de Referência da Assistência Social (CRAS). O livro contém capítulos que tratam especificamente da assistência na proteção social especial, de média e alta complexidade, cujo dispositivo de referência é o Centro de Referência Especializado de Assistência Social (CREAS).

Chama atenção ainda o rol de autores que compõem este livro-texto. São docentes, pesquisadores e profissionais com experiência na política de assistência social. Alguns, além de estudarem, em cursos de mestrado e doutorado em psicologia social, o campo da assistência social, também atuam diretamente em alguns de seus dispositivos.

Apesar da didática do livro, mencionada acima, um fator que poderá provocar desconforto ao/à leitor/a é a paragrafação. No geral, os capítulos possuem parágrafos longos (existe página com um único parágrafo), o que torna a leitura menos fluida e cansativa. Tal limitação, entretanto, não invalida o relevante conteúdo textual. Feito esse breve preâmbulo, nas linhas seguintes apresentaremos a estrutura do livro.

A obra foi organizada por Lílian Rodrigues da Cruz (UFRGS), Neuza Maria de Fátima Guareschi (UFRGS) e Bruna Moraes Battistelli (UFRGS). Ela é constituída por treze capítulos, nos quais os/as autores/as abordam as questões a partir de uma relação com o contexto social, econômico e político em que estão inseridos.

O capítulo introdutório, Cartas à Assistência Social, é tecido por meio de uma forma de escrita não usual no cenário acadêmico: a carta. Nele, as autoras Bruna Moraes Battistelli e Lílian Rodrigues da Cruz, em um formato dialógico, discorrem sobre o cotidiano de trabalho na política de assistência social, tendo como pano de fundo a conjuntura social e política a qual vivenciaram a partir de 2016.

São produzidas quatro cartas remetidas a diferentes destinatários. A primeira, endereçada a todos os que trabalham na área da assistência social, busca refletir sobre o que as autoras denominam processo de desmonte da política de assistência social, pautado sob a égide do neoliberalismo que, segundo elas, põe em risco os direitos sociais.

A segunda carta, direcionada aos profissionais que realizam a acolhida na política de assistência social, reflete sobre a visão que estes possuem acerca do/a usuário/a, da forma como se propõem a contar suas históricas e do tipo de relação que se pretende estabelecer com eles. A terceira, cujo destinatário é a Assistência 
Social, busca cumprimentá-la pela oportunização de um espaço de trabalho aos psicólogos que, mesmo não compreendendo muito bem o seu papel na assistência social, vêm se aventurando nesse campo.

A última carta é enviada pela Assistência Social aos seus trabalhadores. Nela, expressam-se os desafios e limites que perpassam a política pública de assistência social desde o seu início (a exemplo do reduzido orçamento e estereótipos em relação aos seus destinatários).

Apesar do uso de formas diferentes de redação acadêmica ser legítimo, as notas produzidas nesse capítulo-ensaio devem ser observadas com ressalvas pelo/a leitor/a, já que as autoras partem de um lugar de fala situado. Sendo assim, algumas discussões são reportadas sem sólida fundamentação, aproximando-se da visão de mundo pessoal das autoras. Como exemplo, pode-se citar o questionamento destas ao chamado pente fino realizado pelo governo federal no Programa Bolsa Família, ano de 2017, que bloqueou o benefício de algumas famílias. "Por que o interesse insistente no Bolsa Família?"

O/a leitor/a observará que elas não partem da concepção de irregularidades na aquisição do benefício, em que a existência de fraudes, além de afetar os gastos públicos, representa uma violação àqueles que realmente necessitam do Bolsa Família. Assim, nota-se que as autoras tangenciam a questão, trilhando um percurso argumentativo que expressa mais uma visão pessoal.

No segundo capítulo, É possível libertar a psicologia? Caminhos em direção à psicologia da libertação, Maria Luiza Rovaris Cidade e Pedro Paulo Gastalho de Bicalho, tendo como referência a obra de Martin-Baró e da psicóloga brasileira Silvia Lane, buscam refletir sobre os caminhos em direção a psicologias da libertação no contexto latino-americano. Para tanto, os autores, incialmente, recuperam um pouco da história da constituição da psicologia como ciência, sua relação com o positivismo e as práticas hegemônicas em psicologia ao longo dos anos. As linhas finais do texto são destinadas à discussão da possibilidade de libertação da psicologia, a partir dos pressupostos da psicologia da libertação e do compromisso social.

O vínculo familiar e comunitário como operador que conecta a psicologia e a política de assistência social é título do capítulo três. Nele, Luciana Rodrigues e Neuza Maria de Fátima Guareschi apresentam o vínculo, enquanto operador presente tanto na psicologia quanto na política de assistência social, como um conector estratégico que possibilita a articulação entre as duas áreas. Ademais, além de conectar essas duas redes distintas, esse conector também representa um ponto de ancoragem para a atuação do/a psicólogo/a no âmbito dessa política.

Um ponto no capítulo que deve ser visto com ressalva pelo/a leitor/a é a afirmação das autoras de que o CRAS "tem como equipe mínima de referência (independente do porte do município) profissionais de nível superior que incluem [...], preferencialmente, um psicólogo" (Rodrigues \& Guareschi, 2019, p. 58). Com a 
Resolução no 17/2011, que atualiza a NOB-RH/SUAS/06, o psicólogo passou a integrar, de forma obrigatória, a equipe de referência do CRAS (Brasil, 2011).

No capítulo seguinte, O Trabalho na política de assistência social: contribuições da análise do trabalho como atividade, Helena de la Rosa da Rosa e Fernanda Spanier Amador problematizam as formas de trabalhar e subjetivar na política de assistência social, a partir do trabalho em um Centro de Referência Especializado de Assistência Social (CREAS). As autoras utilizam a perspectiva de atividade, tendo como marco teórico condutor o pensamento foucaltiano de governamentalidade e biopolítica e, ainda, a macro e micropolítica de Deleuze e Guattari.

A psicologia e a produção do perigo no SUAS. Caminhos perigosos? intitula o capítulo cinco. Escrito por Adriana Garritano Dourado e Andrea Scisleski, o texto revela como a práxis psicológica no SUAS reverbera a lógica do controle e vigilância, a partir da produção do perigo (o perigoso é aquele fora dos padrões), funcionando como dispositivo de segurança junto ao público atendido, policiando e normatizando sua conduta.

O capítulo seis, desenvolvido por Anete Regina da Cunha e Luis Artur Costa, traz como título a Religião e a assistência na salvação pelo trabalho: governamentos da pobreza em uma mirada genealógica. Neste escrito, os autores abordam a relação entre a religião e a política de assistência social, indicando como a prática de caridade e benemerência cristã continua perpassando o trabalho no campo da assistência social, implicando em modos de controle da pobreza.

Prosseguindo o debate em relação à noção de caridade e controle da pobreza, no texto "Não estávamos seguros" - tensionamentos entre os discursos do direito e da caridade no campo da assistência social, Gabrielly da Fontoura Winter e Betina Hillesheim analisam os discursos enunciados no jornal Zero Hora (importante meio de comunicação do sul do país) a respeito da assistência social. Nestes, as autoras identificam concepções que relacionam a assistência social a práticas de caridade, excluindo desta a noção de direitos sociais.

No capítulo oito, O silenciamento da violência, produzido por Marisa Batista Warpechowski e Luciane De Conti, o/a leitor/a apreciará um texto que trata da violência vivenciada por adolescentes em contexto de vulnerabilidade e exclusão social. Por meio de uma abordagem crítica, as autoras buscam desnaturalizar tal fenômeno, examinando a sua incidência entre os jovens da periferia de Porto Alegre. Para esse propósito, elas inicialmente discutem o aumento da violência nessa parcela da população, com destaque para o crescente número de homicídios.

Ganha contorno, também, a menção à violência cometida pelo próprio Estado contra aos adolescentes da periferia, por meio da repressão policial ou da precarização das políticas públicas, contribuindo para o aumento da violência e das mortes, já que se reduz as possibilidades de inclusão da população. O capítulo é finalizado com a apresentação de uma experiência de escuta a um grupo de 
adolescentes acolhidos em um CREAS que, por meio de atividades de rodas de conversas, encontraram um espaço para escuta, acompanhamento, trocas de experiências e discussão acerca da violência.

Em "Corações de papel reciclável": encontros e desencontros na socioeducação, Maria Dornelles de Araújo Ribeiro e Sandra Djambolakdjian Torossian tratam das medidas socioeducativas no contexto brasileiro. Para tanto, retratam a história de um adolescente em acompanhamento no Programa de Oportunidades e Direitos (POD Socioeducativo), em uma Fundação na cidade de Porto Alegre, RS.

O adolescente, chamado de Vini, por meio de um blog reconta sua história de vida e sua experiência durante a participação no programa. As narrativas transparecem os encontros e desencontros em meio às condicionalidades impostas pelo programa, as quais Vini tem dificuldades para cumpri-las.

Seguindo essa linha, o capítulo "Socorro, meus filhos estão no abrigo!": histórias do/no acolhimento institucional, escrito por Bruna Moraes Battistelli, Neuza Maria de Fátima Guareschi e Lílian Rodrigues da Cruz, discute o acolhimento institucional de crianças e adolescentes vítimas de situação de negligência e violência, a partir da narrativa do caso de Maria, uma mãe que tem cinco filhos (do total de seis) em acolhimento institucional. São mencionados os efeitos da judicialização e do controle institucional na dinâmica das relações e vida dos acolhidos, bem como as dificuldades em se adequar às rígidas prescrições de rotina no acolhimento institucional.

No capítulo dez, Vulnerabilidade e acesso: espaços de resistência e negociações nas políticas sociais, Camilla Fernandes Marques, Anita Guazzelli Bernardes e Priscilla Lorenzini Fernandes de Oliveira abordam a relação entre o acesso às políticas sociais e a vulnerabilidade. O objetivo é refletir sobre a de modos de negociação com as formas de condução de condutas.

Alexandre Missel Knorre apresenta o capítulo "Rádio no livro": o dispositivo clínico "Rádio na Rua" em movimento de escrita, em que narra o contexto de desenvolvimento do dispositivo "Rádio nas Ruas", ferramenta utilizada para o trabalho com pessoas em situação de rua, em diferentes espaços da cidade. $O$ texto é escrito de forma diferenciada, a partir de diálogos entre personagens que narram essa experiência.

O último capítulo, Ortopedias políticas e a produção de "mulheres universais" na Política Nacional de Assistência Social (PNAS), formulado por Simone Maria Hüning e Érika Cecília Soares Oliveira, problematiza a normatização das subjetividades femininas nas políticas públicas de assistência social, na qual a inclusão da mulher ocorre por meio de uma cidadania limitada e modelada por uma lógica neoliberal e patriarcal, onde estão presentes as identidades de mãe, esposa e mulher ideal.

À guisa de conclusão, podemos destacar que a presente obra resenhada é enriquecida pela variedade conceitual, teórica e de escrita que a perpassa ao longo 
dos trezes capítulos. Desta forma, oferece ao leitor uma gama de possibilidades metodológicas.

Os capítulos que a compõem são articulados em uma perspectiva crítica que objetiva analisar o campo das políticas públicas de assistência social, contribuindo para subsidiar tanto teoricamente quanto de forma prática a atuação em psicologia nessa política pública. Sendo assim, o livro é de suma importância para profissionais (que buscam atualização), estudantes e pesquisadores da psicologia social.

\section{REFERÊNCIAS}

Brasil, Conselho Nacional de Assistência Social (CNAS). (2011). Resolução $n^{\circ}$ 17, de 20 de junho de 2011. Brasília, DF: Diário Oficial da União.

Macedo, J. P., \& Dimenstein, M. (2011). Expansão e interiorização da psicologia: Reorganização dos saberes e poderes na atualidade. Psicologia: Ciência e Profissão, 31(2), 296-313. https://doi.org/10.1590/S1414-98932011000200008

Rodrigues, L., \& Guareschi, N. M. F. (2019). O vínculo familiar e comunitário como operador que conecta a psicologia e a política de assistência social. In L. R. Cruz, N. M. F. Guareschi, \& B. M. Battistelli (Eds). Psicologia e assistência social: Encontros possíveis no contemporâneo (pp. 52-65). Petrópolis, RJ: Vozes.

\section{AGRADECIMENTOS}

Ao Kairon Robert pela motivação diária.

\section{CONFLITOS DE INTERESSES}

Não há conflitos de interesses.

\section{SOBRE O AUTOR}

Kairon Pereira de Araújo Sousa é psicólogo pela Universidade Estadual do Piauí - UESPI, licenciado em filosofia pela Universidade Federal do Piauí - UFPI, mestre em psicologia pelo PPGPSI da UFPI e doutorando em Psicologia em Saúde e Desenvolvimento pela Universidade de São Paulo - Faculdade de Filosofia, Ciências e Letras de Ribeirão Preto (FFCLRP-USP). Possui experiência profissional nas seguintes áreas da psicologia: psicologia social, psicologia educacional/escolar e psicologia clínica. E-mail: kaironpereira@hotmail.com

(1) https://orcid.org/0000-0003-0779-343X 